\title{
Racial and Ethnic Disparities in Diagnosis of Chronic Medical Conditions in the USA
}

\author{
Eun Ji Kim, MD, MS, MS ${ }^{7}$, Taekyu Kim, MBA ${ }^{2}$, Joseph Conigliaro, MD, $M P H^{7}$, \\ Jane M. Liebschutz, MD, MPH ${ }^{3}$, Michael K. Paasche-Orlow, MD, MA, MPH ${ }^{4}$, and \\ Amresh D. Hanchate, $P h D^{4,5}$ \\ 'Division of General Internal Medicine, Donald and Barbara Zucker School of Medicine at Hofstra/Northwell, Lake Success, NY, USA; \\ ${ }^{2}$ Massachusetts General Hospital, Boston, MA, USA; ${ }^{3}$ Division of General Internal Medicine, University of Pittsburgh, Pittsburgh, PA, USA; ${ }^{4}$ Section of \\ General Internal Medicine, Boston University School of Medicine, Boston, MA, USA; 5 VA Boston Healthcare System, Boston, MA, USA.
}

BACKGROUND: There exist racial and ethnic disparities in the prevalence of chronic medical illnesses. However, it is unclear if the disparities arise from patients' selfreported estimates on these diseases and whether there is an association between healthcare utilization and diagnosis.

OBJECTIVE: To estimate national racial/ethnic prevalence of undiagnosed hypertension, diabetes, high cholesterol, and kidney disease and identify characteristics associated with undiagnosed diseases.

DESIGN: Retrospective analysis of multi-year survey data.

PARTICIPANTS: Adults 18 years and older who participated in the National Health and Nutrition Examination Survey during 2011-2014 ( $n=10,403)$.

MAIN OUTCOMES: Undiagnosed hypertension (SBP $\geq$ 140 or $\mathrm{DBP} \geq 90$ on physical examination with no history of hypertension), undiagnosed diabetes (hgbalc $\geq 6.5 \%$ with no history of diabetes), undiagnosed high cholesterol (LDL $\geq 160 \mathrm{mg} / \mathrm{dL}$ with no history of high cholesterol), and undiagnosed kidney disease (eGFR $\leq 30$ with no history of kidney disease).

RESULTS: The study sample was categorized into Whites, Blacks, Hispanics, Asians, and Other. After adjusting for sociodemographic characteristics, Asians had increased odds of undiagnosed hypertension $(\mathrm{OR}=$ 1.41 [1.06-1.86]) and diabetes $(\mathrm{OR}=6.16$ [3.76-10.08]) compared to Whites. Blacks (OR=2.53 [1.71-3.73]) and Hispanics (OR = 1.88 [1.19-2.99]) had increased odds of undiagnosed diabetes compared to Whites. Multivariate logistic regression analysis indicated that not having any health insurance was associated with increased odds of undiagnosed diabetes and hyperlipidemia $(\mathrm{OR}=1.56$ [1.00-2.44] and OR=2.08 [1.44-3.00], respectively). A recent healthcare visit was associated with a lower likelihood of having undiagnosed hypertension $(\mathrm{OR}=0.58$ [0.41-0.83]) and diabetes (OR=0.35 [0.18-0.69]).

$\overline{\text { Earlier version of this work was presented at the Society for General }}$ Internal Medicine annual meeting (Washington, DC, April 2017).

Electronic supplementary material The online version of this article (https://doi.org/10.1007/s11606-018-4471-1) contains supplementary material, which is available to authorized users.

Received October 26, 2017

Revised February 13, 2018

Accepted April 24, 2018

Published online May 7, 2018
CONCLUSIONS: In a nationally representative cohort, Asians had higher rates of undiagnosed hypertension and diabetes, and all minorities were more likely to have undiagnosed diabetes compared to Whites. Healthcare utilization was associated with undiagnosed medical conditions. Our study showed that reliance on self-reported data may systemically underestimate the prevalence of chronic illnesses among minorities and further research is needed to understand the significance of healthcare utilization in health outcomes.

KEY WORDS: health disparity; hypertension; diabetes; NHANES.

$\mathrm{J}$ Gen Intern Med 33(7):1116-23

DOI: $10.1007 / \mathrm{s} 11606-018-4471-1$

(c) Society of General Internal Medicine 2018

\section{INTRODUCTION}

Hypertension and diabetes are common diseases in the USA, affecting 30 and 12-14\% of adults, respectively. ${ }^{1,2}$ Epidemiologic studies, based largely on surveys of self-reported health status, show that minorities, including Asian Americans and Hispanics, have a lower prevalence of hypertension and diabetes compared to other race/ethnic groups. ${ }^{3,4}$ Recent studies, however, have shown the contrary, with Asians and Hispanics having a high prevalence of diabetes. ${ }^{2,5}$ Based on these studies, it is important to study if racial and ethnic disparities in self-reported chronic diseases represent the true prevalence or underestimate the prevalence due to the lack of a diagnosis.

National governmental panels and specialty societies have made screening recommendations to identify patients with common medical conditions. ${ }^{6-9}$ The purposes of these screening recommendations are to identify high risk subpopulations and provide medical care to improve public health outcomes. Despite these screening recommendations, minorities have lower rates of screening and subsequently lower rates of awareness, treatment, and control of their diseases compared to non-Hispanic Whites. ${ }^{1,10,11}$ In addition, anchoring on previous beliefs that some minorities, including Asians, have lower prevalence of common medical conditions may adversely affect the screening of these groups and potentially worsen disparities. 
As different undiagnosed medical problems may arise from a common source of factors, we examined a range of chronic medical conditions (hypertension, diabetes, high cholesterol, and kidney disease) using data from the National Health and Nutrition Examination Survey (NHANES). We examined the association between the prevalence of undiagnosed disease and the presence of a routine healthcare provider and evidence of recent healthcare utilization. In addition, we examined the role of race/ethnicity in these associations, with Asian Americans as a distinct group, given evidence of distinct utilization patterns for Asian Americans.

\section{METHODS}

\section{Data}

We used data from the 2011-2014 NHANES, ${ }^{12}$ a biennial nationally representative survey that contains self-reported information on socio-demographic background and health status, physical examinations, and laboratory tests. We used the last 2 cycles of the NHANES data because the survey only started identifying and oversampling Asians in 2011-2012.

\section{Study Population}

The data contains 19,931 participants. Our study cohort consisted of all survey respondents 18 years or older who (1) responded to survey questionnaires on health status, (2) underwent a physical examination with blood pressure and body mass index (BMI) measurements, and (3) had hemoglobin alc (hgbalc), low-density lipoprotein (LDL), and creatinine laboratory measures. We excluded 7960 participants who were younger than 18 years old and 1568 participants with invalid/incomplete responses to the main covariates (six had missing sociodemographic characteristic variables, 1098 had invalid/incomplete physical examination, 461 had missing laboratory measures, and three had missing responses to healthcare utilization questions).

\section{Primary Outcome}

The main outcomes were undiagnosed hypertension, diabetes, high cholesterol, and kidney disease. We defined undiagnosed disease as having self-reported no previous diagnosis of a given disease, but having abnormal blood pressure measurements, laboratory test, or estimated physiologic rate at the time of the research interview and data collection. The discordance between the self-report and the evidence obtained at the time of the research exam defined the status of having an undiagnosed disease. Undiagnosed hypertension was defined as having systolic blood pressure $\geq 140 \mathrm{mmHg}$ or diastolic blood pressure $\geq 90 \mathrm{mmHg}$ on physical examination with no history of hypertension. The physical examination data included 1 to 4 blood pressure readings done at a single visit; in cases of multiple readings, we used the average to identify elevated BP status. Among 10,403 participants, 9673 had three blood pressure readings, 692 had two readings, and 38 had only one reading. We defined participants as having a history of hypertension if they self-reported themselves as (1) having been diagnosed of high blood pressure by a doctor on two or more settings (Question: Are you told on two or more different visits that you had hypertension, also called high blood pressure?) or (2) having taken anti-hypertensive medication(s) (Question: Because of your high blood pressures/hypertension, have you ever been told to take prescribed medicine?). For other diseases, we defined participants as reporting a history of diabetes, high cholesterol, or kidney disease if they were told by a doctor or health professional that they have the diseases (Questions: Other than during pregnancy, have you ever been told by a doctor or health professional that you have diabetes or sugar diabetes? Have you ever been told by a doctor or other health professional that your blood cholesterol level was high? Have you ever been told by a doctor or other health professional that you had weak or failing kidneys?). Undiagnosed diabetes was defined as having hgbalc $\geq 6.5 \%$, while reporting no history of diabetes, undiagnosed high cholesterol was defined as having $\mathrm{LDL} \geq 160 \mathrm{mg} / \mathrm{dL}$ while reporting no history of high cholesterol, and undiagnosed kidney disease was defined as having an estimated glomerular filtration rate (eGFR) less than 30 while reporting no history of kidney disease. ${ }^{6,9,13}$ Estimated GFR was calculated using the Modification of Diet in Renal Disease (MDRD) equation. ${ }^{14}$

\section{Race/Ethnicity}

We used self-reported race/ethnicity and categorized the race and ethnicity indicators into five groups: nonHispanic Whites, non-Hispanic Blacks, Hispanics, Asians, and Others. We were not able to identify the ethnic backgrounds of Asians due to the lack of national origin information in the survey.

\section{Covariates}

We identified key sociodemographic, clinical, and healthcare utilization characteristics associated with differential risk of undiagnosed chronic conditions. For socio-demographic variables, we included gender, age, educational level, income status, and insurance. ${ }^{15-20}$ To adjust for differences in the prevalence of medical conditions among different age groups, we categorized age into four groups: 18-34, 35-49, 50-64, and $65+$. Educational achievement was categorized into three groups: less than high school diploma, high school diploma or equivalent, and education higher than high school. Lowincome status was defined as family income $\leq 100 \%$ of the Federal Poverty Level. We also included BMI as a covariate due to BMI-specific screening recommendations for hypertension and diabetes. BMI was categorized into four groups: underweight $\left(<18.5 \mathrm{~kg} / \mathrm{m}^{2}\right)$, normal weight $(18.5-24.9 \mathrm{~kg} /$ $\left.\mathrm{m}^{2}\right)$, overweight $\left(25.0-29.9 \mathrm{~kg} / \mathrm{m}^{2}\right)$, and obese $(\geq 30.0 \mathrm{~kg} /$ $\mathrm{m}^{2}$ ). For healthcare utilization characteristics, we examined whether participants reported a routine place to go for 
healthcare and whether they reported any healthcare visit in the past year.

The survey was administered in person at the participant's residence using a computer-assisted personal interviewing system. Respondents were offered the choice of being interviewed in English or Spanish using a questionnaire, and if either version of the questionnaire was not adequate, participants were provided with an interpreter.

\section{Statistical Analysis}

In all our statistical analyses, we incorporated the multistage stratification sampling design and sampling weights. $^{21}$ "Other" racial/ethnic group was included in all the analysis but not presented in the results due to the small number of participants $(n=313)$. To characterize the sample population by race/ethnicity, we compared the unadjusted prevalence of socio-demographic indicators, measures of healthcare utilization, and undiagnosed chronic diseases. We also compared the combined prevalence of chronic conditions including the undiagnosed rate along with the self-reported rate. The Holm-Bonferroni sequential method was applied to account for multiple comparisons. $^{22}$ To compare the prevalence of undiagnosed chronic conditions while accounting for differences in the covariates, we estimated two multivariate logistic models with an indicator of undiagnosed condition as the outcome. In the first model, we adjusted for socio-demographic indicators, and in the second model, we also adjusted for healthcare utilization indicators (having a place for routine healthcare and having any healthcare visit within the past year). We performed sensitivity analysis to examine the prevalence of undiagnosed high cholesterol using lower thresholds (LDL $\leq 130)$ (Appendix A online). We also examined whether limited English proficiency was associated with the likelihood of undiagnosed diseases, particularly among Asians and Hispanics. Participants were identified as having limited English proficiency if they used the Spanish questionnaire or an interpreter for the survey interview.

All statistical analyses were conducted using SAS 9.4 (SAS Institute Inc., Cary, NC. USA). The Boston University IRB reviewed and exempted the study.

\section{RESULTS}

The study sample of 10,403 was categorized into five groups (weighted percentages): non-Hispanic Whites $(66.6 \%)$, non-Hispanic Blacks (11.1\%), Hispanics $(14.5 \%)$, Asians $(5.0 \%)$, and Others $(2.7 \%)$. There were significant differences in sociodemographic, clinical, and healthcare utilization characteristics among the different racial/ethnic groups ( $P$ value for chi-square test of similarity of rates across race/ethnic groups all less than 0.01) (Table 1). There were significant differences in the percentages of racial/ethnic groups with low income and
Table 1 Characteristics of Study Sample by Race/Ethnicity (Weighted \%)

\begin{tabular}{|c|c|c|c|c|c|}
\hline & \multirow{2}{*}{$\begin{array}{l}\text { Whites } \\
(n= \\
4153)\end{array}$} & \multirow{2}{*}{$\begin{array}{l}\text { Blacks } \\
(n= \\
2384)\end{array}$} & \multirow{2}{*}{$\begin{array}{l}\text { Hispanics } \\
(n= \\
2260)\end{array}$} & \multirow{2}{*}{$\begin{array}{l}\text { Asians } \\
(n= \\
1293)\end{array}$} & \multirow{2}{*}{$\begin{array}{l}P \\
\text { value }^{\text {a }}\end{array}$} \\
\hline & & & & & \\
\hline \multicolumn{6}{|c|}{ Socio-demographic characteristics } \\
\hline Male & 49.1 & 44.8 & 50.1 & 46.4 & 0.01 \\
\hline \multicolumn{6}{|l|}{ Age group } \\
\hline $18-34$ & 25.9 & 35.5 & 40.9 & 32.8 & $<0.01$ \\
\hline $35-49$ & 24.5 & 27.0 & 32.8 & 32.7 & \\
\hline $50-64$ & 29.0 & 25.8 & 18.1 & 21.6 & \\
\hline 65 or older & 20.6 & 11.8 & 8.2 & 12.9 & \\
\hline \multicolumn{6}{|l|}{ Education } \\
\hline Less than & 10.9 & 19.5 & 39.7 & 11.9 & $<0.01$ \\
\hline \multicolumn{6}{|l|}{ HS } \\
\hline $\begin{array}{l}\text { HS or } \\
\text { equivalent }\end{array}$ & 20.4 & 25.6 & 21.8 & 13.8 & \\
\hline $\begin{array}{l}\text { Higher } \\
\text { than HS }\end{array}$ & 68.7 & 54.9 & 38.5 & 74.2 & \\
\hline Low & 10.9 & 30.9 & 31.7 & 13.6 & $<0.01$ \\
\hline $\begin{array}{l}\text { income } \\
\text { No } \\
\text { insurance }\end{array}$ & 12.4 & 24.7 & 42.4 & 17.7 & $<0.01$ \\
\hline \multicolumn{6}{|c|}{ Healthcare utilization characteristics } \\
\hline \multicolumn{6}{|c|}{ Have a routine place to go for healthcare } \\
\hline Yes & 87.2 & 87.0 & 71.3 & 78.9 & $<0.01$ \\
\hline \multicolumn{6}{|c|}{ Have a healthcare visit in the past year } \\
\hline Yes & 88.1 & 85.7 & 72.4 & 79.9 & $<0.01$ \\
\hline \multicolumn{6}{|c|}{ Have a routine place to go and have a healthcare visit in the past year } \\
\hline Yes & 80.1 & 78.9 & 60.7 & 69.3 & $<0.01$ \\
\hline
\end{tabular}

no insurance (low income Whites $=10.9 \%$, Blacks $=30.9 \%$, Hispanics $=31.7 \%$, Asians $=13.6 \%$; no insurance Whites $=$ $12.4 \%$, Blacks $=24.7 \%$, Hispanics $=42.4 \%$, Asians $=17.7 \%)$. There were also significant differences in the percentages of groups with healthcare utilization (having a routine place for healthcare Whites $=87.2 \%$, Blacks $=87.0 \%$, Hispanics $=$ $71.3 \%$, Asians $=78.9 \%$; having a healthcare visit within the past year Whites $=88.1 \%$, Blacks $=85.7 \%$, Hispanic $=72.4 \%$, Asians $=79.9 \%$ ).

Table 2 shows the clinical characteristics by race and ethnicity. Among Asians, the majority (55.8\%) had normal BMI, whereas, in other groups, the majority of the participants were overweight and obese. There were significant differences in the prevalence of self-reported histories of hypertension, diabetes, and high cholesterol among the different groups. There were also significant racial/ethnic differences in the percentages of participants with elevated blood pressure on physical examination, hgbalc on lab, calculated estimated GFR, and subsequently in the prevalence of undiagnosed diabetes and kidney disease.

After adjusting for covariates (Table 3), Asians were more likely to have undiagnosed hypertension $(\mathrm{OR}=1.41$ [1.061.86]) and diabetes $(\mathrm{OR}=6.16$ [3.76-10.08]) compared to Whites. Blacks $(\mathrm{OR}=2.53$ [1.71-3.73]) and Hispanics $(\mathrm{OR}=$ 1.88 [1.19-2.99]) also had increased odds of undiagnosed diabetes compared to non-Hispanic Whites. There were no significant differences in the likelihood of having undiagnosed 
Table 2 Clinical Characteristics and Observed Rates of Undiagnosed Chronic Illnesses by Race/Ethnicity (Weighted \%)

\begin{tabular}{|c|c|c|c|c|c|}
\hline & Whites & Blacks & Hispanics & Asians & $P$ value $^{a}$ \\
\hline \multicolumn{6}{|l|}{ Body mass index (BMI) } \\
\hline Underweight & 1.5 & 2.0 & 0.9 & 4.2 & \multirow[t]{4}{*}{$<0.01$} \\
\hline Normal & 29.6 & 23.5 & 22.7 & 55.8 & \\
\hline Overweight & 34.2 & 27.4 & 35.0 & 27.9 & \\
\hline Obese & 34.7 & 47.1 & 41.5 & 12.1 & \\
\hline \multicolumn{6}{|l|}{ Hypertension } \\
\hline History of hypertension & 31.4 & 36.4 & 19.6 & 18.9 & $<0.01$ \\
\hline $\mathrm{SBP} \geq 140$ or $\mathrm{DBP} \geq 90$ & 14.3 & 20.2 & 10.5 & 13.1 & $<0.01$ \\
\hline Undiagnosed hypertension & 5.5 & 6.5 & 4.5 & 6.8 & 0.15 \\
\hline \multicolumn{6}{|l|}{ Diabetes } \\
\hline History of diabetes & 8.6 & 12.2 & 9.5 & 9.6 & 0.03 \\
\hline HemoglobinA $1 \mathrm{c} \geq 6.5 \%$ & 6.9 & 11.3 & 9.2 & 10.3 & $<0.01$ \\
\hline Undiagnosed diabetes & 1.4 & 3.4 & 2.5 & 4.2 & $<0.01$ \\
\hline \multicolumn{6}{|l|}{ High cholesterol } \\
\hline History of high cholesterol & 36.8 & 27.5 & 25.6 & 28.5 & $<0.01$ \\
\hline $\mathrm{LDL} \geq 160 \mathrm{mg} / \mathrm{dL}$ & 4.4 & 4.0 & 4.4 & 3.6 & 0.86 \\
\hline Undiagnosed high cholesterol & 1.7 & 2.1 & 2.4 & 1.7 & 0.49 \\
\hline \multicolumn{6}{|l|}{ Kidney disease } \\
\hline History of kidney disease & 2.4 & 2.9 & 2.8 & 1.6 & 0.43 \\
\hline $\mathrm{EGFR} \leq 30$ & 1.8 & 4.4 & 1.8 & 2.4 & $<0.01$ \\
\hline Undiagnosed kidney disease & 1.6 & 3.4 & 1.3 & 2.2 & $<0.01$ \\
\hline
\end{tabular}

${ }^{a} P$ value is based on the chi-square test of similarity of rates across race/ethnic groups and corrected with the Holm-Bonferroni sequential method

high cholesterol among the groups. Blacks were almost twice as likely $(\mathrm{OR}=2.05[1.35-3.10])$ to have undiagnosed kidney disease compared to Whites. Belonging to an older age group was associated with increased odds of having either hypertension or diabetes, and the likelihood of having either disease increased as the age group increased. Males, compared to females, had increased odds $(\mathrm{OR}=1.58$ [1.23-2.02]) of having undiagnosed hypertension but decreased odds of having undiagnosed kidney disease $(\mathrm{OR}=0.62$ [0.45-0.85]). Having no health insurance was associated with an increased likelihood of having undiagnosed diabetes ( $\mathrm{OR}=1.56$ [1.00-2.44]) and undiagnosed high cholesterol $(\mathrm{OR}=2.08$ [1.44-3.00]).

Asians had a higher prevalence of undiagnosed hypertension and diabetes, relative to Whites, even after adjusting for a routine place for healthcare and recent health care (Asians: undiagnosed hypertension $(\mathrm{OR}=1.36$ [1.02-1.81]) and diabetes $(\mathrm{OR}=5.89$ [3.58-9.70])) (Table 4). After adjusting for healthcare utilization, Blacks $(\mathrm{OR}=2.57$ [1.76-3.75]) and Hispanics $(\mathrm{OR}=1.80$ [1.11-2.93]) also had a higher prevalence of undiagnosed diabetes, relative to Whites. Having a healthcare visit in the past year was associated with decreased odds of having undiagnosed hypertension $(\mathrm{OR}=0.58$ [0.41$0.83])$ and diabetes $(\mathrm{OR}=0.35[0.18-0.69])$. Having a routine place for healthcare was associated with decreased odds $(\mathrm{OR}=$ $0.61[0.42-0.89])$ for undiagnosed high cholesterol. Sensitivity analysis using a more stringent definition of high cholesterol (LDL $\geq 130$ ) showed no significant racial/ethnic differences in having undiagnosed high cholesterol. We also

Table 3 Predictors of Undiagnosed Diseases by Race/Ethnicity (Odds Rate [95\% Confidence Interval])

\begin{tabular}{|c|c|c|c|c|}
\hline \multicolumn{5}{|l|}{ Overall sample $(N=10,403)$} \\
\hline & $\begin{array}{l}\text { Undiagnosed } \\
\text { hypertension }\end{array}$ & $\begin{array}{l}\text { Undiagnosed } \\
\text { diabetes }\end{array}$ & $\begin{array}{l}\text { Undiagnosed high } \\
\text { cholesterol }\end{array}$ & $\begin{array}{l}\text { Undiagnosed kidney } \\
\text { disease }\end{array}$ \\
\hline \multicolumn{5}{|c|}{ Race/ethnicity (reference: non-Hispanic Whites) } \\
\hline Blacks & $1.26[0.94-1.69]$ & $2.53[1.71-3.73]^{*}$ & $0.96[0.58-1.57]$ & $2.05[1.35-3.10]^{*}$ \\
\hline Hispanics & $1.00[0.74-1.35]$ & $1.88[1.19-2.99]^{*}$ & $0.79[0.45-1.40]$ & $0.85[0.46-1.58]$ \\
\hline Asians & $1.41[1.06-1.86]^{*}$ & $6.16[3.76-10.08]^{*}$ & $1.04[0.58-1.85]$ & $1.33[0.67-2.61]$ \\
\hline \multicolumn{5}{|c|}{ Age group (reference: $18-34$ years old) } \\
\hline $35-49$ & $2.58[1.60-4.17]^{*}$ & $3.89[1.97-7.67]^{*}$ & $1.73[1.16-2.59]^{*}$ & $0.79[0.44-1.43]$ \\
\hline $50-64$ & $4.27[2.97-6.13] *$ & $5.89[3.11-11.17] *$ & $0.76[0.43-1.36]$ & $1.26[0.67-2.36]$ \\
\hline $65+$ & $5.22[3.72-7.33] *$ & $7.47[3.44-16.23]^{*}$ & $0.78[0.43-1.44]$ & $2.06[1.15-3.70]^{*}$ \\
\hline \multicolumn{5}{|l|}{ Gender (reference: female) } \\
\hline Male & $1.58[1.23-2.02]^{*}$ & $1.52[0.98-2.36]$ & $1.09[0.75-1.59]$ & $0.62[0.45-0.85]^{*}$ \\
\hline \multicolumn{5}{|c|}{ Education (reference: more than high school) } \\
\hline High school of equivalent & $1.37[0.99-1.91]$ & $0.76[0.44-1.34]$ & $0.71[0.42-1.19]$ & $0.84[0.55-1.27]$ \\
\hline Less than high school & $0.92[0.66-1.28]$ & $0.73[0.44-1.22]$ & $0.56[0.32-0.99]^{*}$ & $0.50[0.34-0.72]^{*}$ \\
\hline \multicolumn{5}{|c|}{ Income (reference: ratio of family income to poverty $\geq 100 \%$ ) } \\
\hline Low income & $0.93[0.66-1.28]$ & $0.91[0.56-1.50]$ & $1.05[0.71-1.55]$ & $1.12[0.73-1.71]$ \\
\hline \multicolumn{5}{|c|}{ Insurance (reference: have insurance) } \\
\hline No insurance & $1.23[0.88-1.71]$ & $1.56[1.00-2.44]^{*}$ & $2.08[1.44-3.00]^{*}$ & $0.90[0.52-1.56]$ \\
\hline \multicolumn{5}{|c|}{ Body mass index (reference: normal) } \\
\hline Underweight & $1.34[0.57-3.16]$ & - & $0.59[0.11-3.25]$ & $1.05[0.50-2.18]$ \\
\hline Overweight & $0.65[0.43-0.98]^{*}$ & $1.97[0.93-4.14]$ & $1.72[0.97-3.05]$ & $0.47[0.29-0.76]^{*}$ \\
\hline Obese & $0.92[0.63-1.36]$ & $7.33[3.20-16.79]^{*}$ & $1.55[0.84-2.86]$ & $0.80[0.51-1.27]$ \\
\hline
\end{tabular}

$* P$ value $<0.05$ 
Table 4 Predictors of Undiagnosed Diseases by Race/Ethnicity, Adjusted for Healthcare Utilization Characteristics (Reference: Non-Hispanic Whites)

\begin{tabular}{|c|c|c|c|c|}
\hline & $\begin{array}{l}\text { Undiagnosed } \\
\text { hypertension }\end{array}$ & $\begin{array}{l}\text { Undiagnosed } \\
\text { diabetes }\end{array}$ & $\begin{array}{l}\text { Undiagnosed high } \\
\text { cholesterol }\end{array}$ & $\begin{array}{l}\text { Undiagnosed kidney } \\
\text { disease }\end{array}$ \\
\hline $\begin{array}{l}\text { Blacks } \\
\text { Hispanics } \\
\text { Asians } \\
\text { Routine place for healthcare } \\
\text { Healthcare visit in the past } \\
\text { year }\end{array}$ & $\begin{array}{l}1.28[0.95-1.73] \\
0.96[0.72-1.29] \\
1.36[1.02-1.81]^{*} \\
0.80[0.54-1.17] \\
0.58[0.41-0.83]^{*}\end{array}$ & $\begin{array}{l}2.57[1.76-3.75]^{*} \\
1.80[1.11-2.93]^{*} \\
5.89[3.58-9.70]^{*} \\
1.32[0.76-2.31] \\
0.35[0.18-0.69]^{*}\end{array}$ & $\begin{array}{l}0.98[0.60-1.60] \\
0.77[0.43-1.36] \\
1.01[0.57-1.81] \\
0.61[0.42-0.89]^{*} \\
0.98[0.66-1.46]\end{array}$ & $\begin{array}{l}2.03[1.33-3.09]^{*} \\
0.87[0.47-1.61] \\
1.35[0.69-2.64] \\
1.15[0.67-1.96] \\
1.40[0.74-2.65]\end{array}$ \\
\hline
\end{tabular}

The logistic regression also adjusted for gender, age group (18-34, 35-49, 50-64, and 65+), education (less than high school, HS or equivalent, and higher than HS), low income, and insurance

$* P$ value $<0.05$

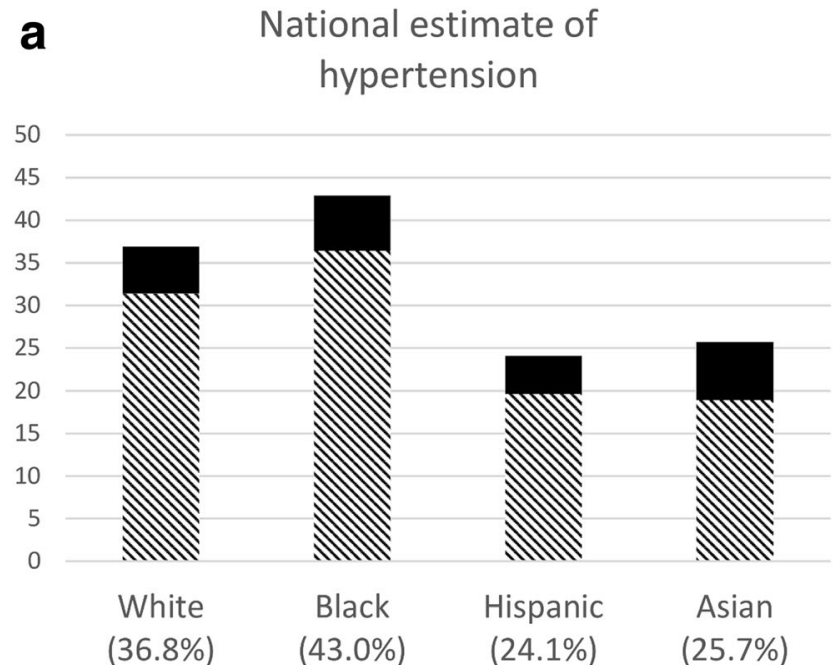

C
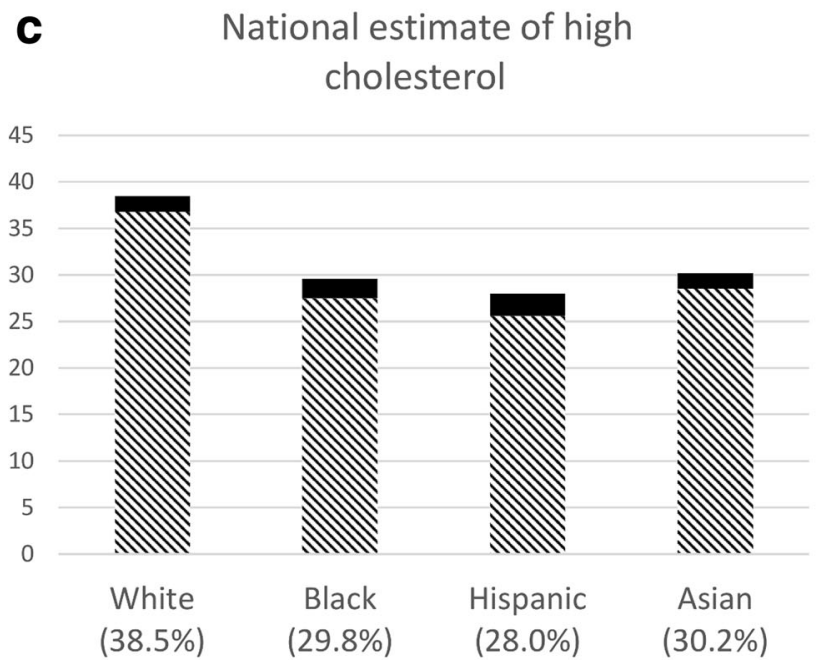

Undiagnosed high cholesterol

N History of high cholesterol b

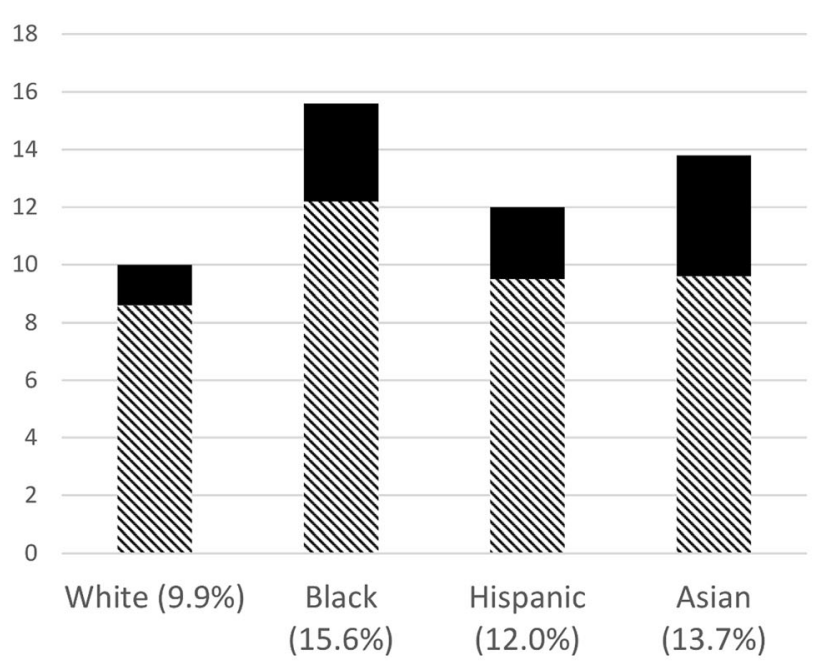

Nistory of diabetes

Undiagnosed diabetes

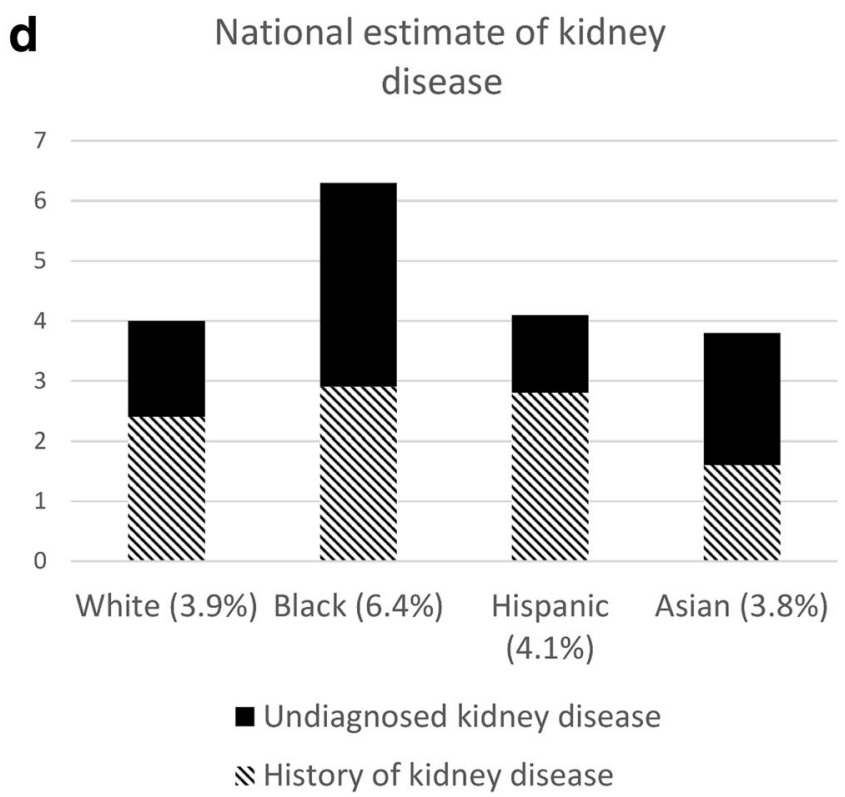

Fig. 1 a National estimate of hypertension. b National estimate of diabetes. c National estimate of high cholesterol. d National estimate of kidney disease. 
conducted a sensitivity analysis, adjusting for limited English proficiency (Appendix B online). We found 0.3\% Whites, 0.4\% Blacks, $43.4 \%$ Hispanics, and $19.2 \%$ Asians to have limited English proficiency. When limited English proficiency was included in the analysis, Asians no longer had an increased likelihood of having undiagnosed hypertension and Hispanics no longer had an increased likelihood of having undiagnosed diabetes compared to Whites.

Lastly, using participants' self-reported diagnosis and our observed rate of undiagnosed diseases, we estimated the national prevalence of chronic medical conditions (Fig. 1). There was a significant difference in the prevalence of kidney disease among different racial and ethnic groups after accounting for the prevalence of undiagnosed diseases.

\section{DISCUSSION}

Using nationally representative data, we found significant racial/ethnic differences in the prevalence of undiagnosed hypertension, diabetes, and kidney disease. Asians had an increased likelihood of having both undiagnosed hypertension and diabetes, while Blacks and Hispanics had a higher likelihood of having undiagnosed diabetes compared to nonHispanic Whites after adjusting for sociodemographic characteristics and BMI. These findings persisted even after adjusting for having a place for routine care and having a healthcare visit in the past year.

There are several plausible explanations for minorities having an increased likelihood of undiagnosed medical conditions. For Asians, anchoring on this belief that Asians have low prevalence of certain common medical conditions, including hypertension and diabetes ${ }^{3,4}$, a smaller percentage of Asians may have sought to screen for these common diseases, and among those who had healthcare visits, their healthcare providers may have had higher thresholds to screen for them. Another possibility is that the prevalence of these common diseases may differ with acculturation, specifically with the adoption of a Western diet. ${ }^{23}$ As immigrant populations adapt to the Western culture, their new disease-risk may have become similar or even higher than the overall US population. ${ }^{24,25}$ Our analysis examining healthcare utilization characteristics showed that Hispanics and Asians may not be utilizing healthcare and thus place them at an increased risk of not having appropriate screening. This pattern of low healthcare utilization is pervasive and includes low cancer screening among adults and healthcare visits among children. ${ }^{26,27}$ This is especially contradictory to Asians, who have favorable sociodemographic characteristics, including high percentages of Asians having high educational achievement, middle-high income, and health insurance. Lastly, recent studies have shown that Asians have a higher percentage of body fat for given BMI, resulting in a higher risk of developing diabetes at lower levels of BMI. ${ }^{28,29}$
Our study identified other characteristics of undiagnosed diseases related to insurance and healthcare utilization. Despite guidelines recommending diabetes screening among obese patients, ${ }^{30}$ we found that individuals who were obese had a sevenfold increased odds of having undiagnosed diabetes. Having no insurance was associated with an increased likelihood of having undiagnosed diabetes and high cholesterol. A diagnosis of hypertension can be more conveniently done using blood pressure machines available in public settings (e.g., drug stores and supermarkets), independent of insurance. In contrast, a diagnosis of diabetes requires laboratory tests or a glucometer, which are less accessible. Additionally, a healthcare visit in the past year was associated with decreased odds of having undiagnosed hypertension and diabetes. As blood pressure and diabetes screening are commonly done during healthcare visits, this supports our study's finding. Interestingly, having a routine place for healthcare was associated with the diagnosis of high cholesterol, but having a healthcare visit in the past year was not. One possibility is that additional laboratory testing, such as lipid screening, is done during routine healthcare visits, as abnormal lab findings require follow-up visits.

Our analysis to address limited English proficiency as a factor in the diagnosis of medical conditions showed that limited English proficiency was associated with a diagnosis of diabetes. Also, adjusting for limited English proficiency resulted in the mitigation of differences in the diagnosis of hypertension among Asians and the diagnosis of diabetes among Hispanics compared to Whites. This showed that differences in the diagnosis arose from limited English proficiency in certain situations, and improving patient-physician communication by utilizing interpreters could potentially increase the diagnosis of these medical conditions.

We believe that the basis of screening for these common medical conditions is multifactorial. For common diseases such as hypertension, there is wide acceptability of existing guidelines. For high cholesterol and kidney diseases, guidelines exist, but there are conflicting recommendations regarding which population should be screened and significant variations in the target screening group. ${ }^{8,31}$ Additionally, screening may be influenced by the prevalence and comorbidities associated with these diseases. Hypertension, a comorbid condition for various medical conditions, has resulted in an increased awareness and diagnosis of common diseases. Lastly, the national estimate of undiagnosed diseases can be influenced by the use of confirmatory diagnoses. For diabetes, the prevalence of undiagnosed diabetes differs significantly based on whether a single laboratory measurement is used versus a confirmatory diagnosis (either presence of overt symptoms or second blood sample test). ${ }^{5}$

There are several limitations to this study. We used retrospective cross-sectional data; therefore, the findings do not indicate a causal relationship between race/ethnicity and undiagnosed medical conditions. Also, not all variables of interest were available. Information on the types of healthcare 
visits would help differentiate healthcare seeking behaviors among different groups. For example, if minorities are more likely to seek urgent or emergency care, a potential implication of the study is to promote preventive visits. Another limitation arises from having blood pressure measured in a single setting; this may have led to an over-estimation of undiagnosed hypertension. Also, although we adjusted for limited English proficiency, we were not able to adjust for health literacy, which is a more accurate measure of a patient's understanding of health information. In addition, we used self-reported information, which could result in the underreporting of medical conditions and medical diagnosis based on comorbidities (e.g., Atherosclerotic Cardiovascular Disease risk or proteinuria). However, studies found that patients diagnosed with hypertension are at least fairly accurate. ${ }^{32-34}$ Lastly, we were not able to identify subgroups of Asians due to the lack of such information. Currently, there are a very limited number of national data sources that identify the national origin of Asians. A study using state-wide data found differences in the prevalence of these common diseases among different subgroups, ${ }^{35}$ and thus, there is a need for data collection on ethnicity at the national level.

There is a public need for improving screening by developing disease-specific outreach programs to improve population health outcomes. Our study found other factors associated with the diagnosis of medical conditions, including not having insurance, being obese, and belonging to a certain age group. By targeting high-risk groups or improving access to healthcare in general, more patients could be aware of their diseases. These preventive measures can result in significant population-level health benefits. ${ }^{36}$

In summary, we found an increased risk of undiagnosed medical conditions among minorities; Asians had higher rates of undiagnosed hypertension and diabetes, and minorities had higher rates of undiagnosed diabetes compared to nonHispanic Whites. As our study showed that minorities have a higher prevalence of undiagnosed medical conditions, reliance on self-reported data and conclusions that have been derived from such work will need to be reevaluated. Future studies should examine the potential sources of these disparities, including the lack of screening ${ }^{37}$ arising at least in part from perceptions that Asians are less likely to have hypertension or diabetes.

Acknowledgements: Dr. Kim was funded by a training grant from the VA Office of Academic Affiliations and supported by the National Center for Advancing Translational Sciences, National Institutes of Health, through BU-CTSI Grant 1UL1TRO01430. The study has been supported by NIMHD grant 1R01MD007705 (PI: Hanchate). The views expressed in this article are those of the authors and do not necessarily represent the views of the Donald and Barbara Zucker School of Medicine at Hofstra/Northwell, the Department of Veterans Affairs, Boston University, Massachusetts General Hospital, University of Pittsburgh, or National Institutes of Health.

Corresponding Author: Eun Ji Kim, MD, MS, MS; Division of General Internal Medicine Donald and Barbara Zucker School of
Medicine at Hofstra/Northwell, Lake Success, NY, USA (e-mail: ekim7@northwell.edu).

Funders Eun Ji Kim was funded by a training grant from the VA Office of Academic Affiliations and supported by the National Center for Advancing Translational Sciences, National Institutes of Health, through BU-CTSI Grant 1UL1TR001430. The study has been supported by NIMHD grant 1R01MD007705 (PI: Hanchate).

\section{Compliance with Ethical Standards:}

Conflict of Interest: The authors declare that they do not have a conflict of interest.

\section{REFERENCES}

1. Nwankwo T, Yoon SS, Burt V, Gu Q. Hypertension among adults in the United States: National Health and Nutrition Examination Survey, 20112012. NCHS Data Brief. 2013(133): 1-8.

2. Menke A, Casagrande S, Geiss L, Cowie CC. Prevalence of and Trends in Diabetes Among Adults in the United States, 1988-2012. JAMA. 2015;314(10):1021-1029.

3. McNeely MJ, Boyko EJ. Type 2 diabetes prevalence in Asian Americans: results of a national health survey. Diabetes Care. 2004;27(1):66-69.

4. Writing Group M, Lloyd-Jones D, Adams RJ, et al. Heart disease and stroke statistics-2010 update: a report from the American Heart Association. Circulation. 2010;121(7):e46-e215.

5. Selvin E, Wang D, Lee AK, Bergenstal RM, Coresh J. Identifying Trends in Undiagnosed Diabetes in U.S. Adults by Using a Confirmatory Definition: A Cross-sectional Study. Ann Intern Med. 2017;167(11):769-776.

6. Chobanian AV, Bakris GL, Black HR, et al. Seventh report of the Joint National Committee on Prevention, Detection, Evaluation, and Treatment of High Blood Pressure. Hypertension. 2003;42(6):1206-1252.

7. American Diabetes A. Standards of medical care in diabetes-2014. Diabetes Care. 2014;37 Suppl 1:S14-80.

8. ASN emphasized need for early detection of kidney disease, a silent killer [press release]. October 22, 2013

9. Summary of the second report of the National Cholesterol Education Program (NCEP) Expert Panel on Detection, Evaluation, and Treatment of High Blood Cholesterol in Adults (Adult Treatment Panel II). JAMA. 1993;269(23):3015-3023.

10. Okosun IS, Dever GE. Abdominal obesity and ethnic differences in diabetes awareness, treatment, and glycemic control. Obes Res. 2002;10(12):1241-1250.

11. Jerant AF, Fenton JJ, Franks P. Determinants of racial/ethnic colorectal cancer screening disparities. Arch Intern Med. 2008;168(12):1317-1324.

12. National Health and Nutrition Examination Survey (NHANES). http:// www.cdc.gov/nchs/nhanes/: Centers for Disease Control and Prevention 2003-2012 (accessed April 16, 2018).

13. International Expert C. International Expert Committee report on the role of the AlC assay in the diagnosis of diabetes. Diabetes Care. 2009;32(7): 1327-1334.

14. Manjunath G, Sarnak MJ, Levey AS. Prediction equations to estimate glomerular filtration rate: an update. Curr Opin Nephrol Hypertens. 2001;10(6):785-792.

15. Mortality findings for stepped-care and referred-care participants in the hypertension detection and follow-up program, stratified by other risk factors. The Hypertension Detection and Follow-up Program Cooperative Research Group. Prev Med. 1985;14(3):312-335.

16. Winkleby MA, Jatulis DE, Frank E, Fortmann SP. Socioeconomic status and health: how education, income, and occupation contribute to risk factors for cardiovascular disease. Am J Public Health. 1992;82(6):816-820.

17. Race, education and prevalence of hypertension. Am J Epidemiol. 1977;106(5):351-361.

18. van Rossum CT, van de Mheen H, Witteman JC, Hofman A, Mackenbach JP, Grobbee DE. Prevalence, treatment, and control of hypertension by sociodemographic factors among the Dutch elderly. Hypertension. 2000;35(3):814-821

19. Brown CD, Higgins M, Donato KA, et al. Body mass index and the prevalence of hypertension and dyslipidemia. Obes Res. 2000;8(9):605-619. 
20. Guo F, He D, Zhang W, Walton RG. Trends in prevalence, awareness, management, and control of hypertension among United States adults, 1999 to 2010. J Am Coll Cardiol. 2012;60(7):599-606.

21. National Center for Health Statistics: National Health and Nutrition Examination Survey (NHANES)

22. Holm S. A Simple Sequentially Rejective Multiple Test Procedure. Scandinavian Journal of Statistics. 1979;6(2):65-70.

23. Kandula NR, Diez-Roux AV, Chan C, et al. Association of acculturation levels and prevalence of diabetes in the multi-ethnic study of atherosclerosis (MESA). Diabetes Care. 2008;31(8):1621-1628.

24. Keely CB. Effects of the Immigration Act of 1965 on selected population characteristics of immigrants to the United States. Demography. 1971;8(2):157-169.

25. Echeverria SE, Mustafa M, Pentakota SR, et al. Social and clinicallyrelevant cardiovascular risk factors in Asian Americans adults: NHANES 2011-2014. Prev Med. 2017;99:222-227.

26. Kandula NR, Wen M, Jacobs EA, Lauderdale DS. Low rates of colorectal, cervical, and breast cancer screening in Asian Americans compared with non-Hispanic whites: Cultural influences or access to care? Cancer. 2006; 107(1): 184-192.

27. Flores G, Tomany-Korman SC. Racial and ethnic disparities in medical and dental health, access to care, and use of services in US children. Pediatrics. 2008;121(2):e286-298.

28. Ntuk UE, Gill JM, Mackay DF, Sattar N, Pell JP. Ethnic-specific obesity cutoffs for diabetes risk: cross-sectional study of 490,288 UK biobank participants. Diabetes Care. 2014;37(9):2500-2507.
29. Misra A. Revisions of cutoffs of body mass index to define overweight and obesity are needed for the Asian-ethnic groups. Int J Obes Relat Metab Disord. 2003;27(11):1294-1296.

30. American Diabetes A. 2. Classification and Diagnosis of Diabetes. Diabetes Care. 2017;40(Suppl 1):S11-S24.

31. Saunders MR, Cifu A, Vela M. Screening for Chronic Kidney Disease. JAMA. 2015;314(6):615-616.

32. Martin LM, Leff M, Calonge N, Garrett C, Nelson DE. Validation of selfreported chronic conditions and health services in a managed care population. Am J Prev Med. 2000;18(3):215-218.

33. Vargas CM, Burt VL, Gillum RF, Pamuk ER. Validity of self-reported hypertension in the National Health and Nutrition Examination Survey III, 1988-1991. Prev Med. 1997;26(5 Pt 1):678-685.

34. Kehoe R, Wu SY, Leske MC, Chylack LT, Jr. Comparing self-reported and physician-reported medical history. Am J Epidemiol. 1994;139(8):813818 .

35. Karter AJ, Schillinger D, Adams AS, et al. Elevated rates of diabetes in Pacific Islanders and Asian subgroups: The Diabetes Study of Northern California (DISTANCE). Diabetes Care. 2013;36(3):574-579.

36. Farley TA, Dalal MA, Mostashari F, Frieden TR. Deaths preventable in the U.S. by improvements in use of clinical preventive services. Am J Prev Med. 2010;38(6):600-609.

37. Tung EL, Baig AA, Huang ES, Laiteerapong N, Chua KP. Racial and Ethnic Disparities in Diabetes Screening Between Asian Americans and Other Adults: BRFSS 2012-2014. J Gen Intern Med. 2017;32(4):423429 . 